\title{
Atrial Fibrillation in Acute Myocardial Infarction
}

\author{
Radha Bhattarai ${ }^{1}$, Sergey Anatolevich Sayganov ${ }^{1}$ \\ ${ }^{1}$ Department of hospital therapy and cardiology Northwestern State Medical University, \\ Vasilevsky Ostrov, Bolshoe Prospect 85, Saint-Petersburg, Russia.
}

\section{Citation}

Radha Bhattarai, Sergey Anatolevich Sayganov. Atrial Fibrillation in Acute Myocardial Infarction. Nepalese Heart Journal 2015; 12 (1): 15- 20

\section{Key words}

Atrial fibrillation, myocardial infarction, cardioversion.

\section{INTRODUCTION}

Atrial Fibrillation (AF) often occurs in the setting of Acute Myocardial Infarction (AMI), with an incidence between 6 and $21 \%{ }^{1}$ New-onset AF should be differentiated from preexisting AF, since they may have different clinical and therapeutic implications. ${ }^{2,3}$ The prognostic significance of atrial fibrillation, however, varies, depending on

\begin{abstract}
Background and Aim: New-onset atrial fibrillation frequently complicates acute myocardial infarction. The incidence ranges from $6-21 \%$ " 1 ". We aim to determine the incidence of atrial fibrillation in the setting of acute myocardial infarction.
\end{abstract}

Methods: This was a single center prospective study, conductedin the coronary care unitof Saint-Petersburg Pokrovskaya city hospital, Russia, during the period, June 2013 to June 2014. Sixty consecutive patients of acute myocardial infarction with atrial fibrillation were included in this study. Onset, duration, and mode of termination of atrial fibrillation, clinical factors associated with its presentation and its relation with patient outcome were evaluated.

Results: Among the 60 patients 33 (55\%) had inferior wall myocardial infarction and 27 (45\%) patients had anterior wall myocardial infarction. In patients with inferior wall myocardial infarction the onset of atrial fibrillation occurred within 24 hours in 30 (91\%) patients, after 24 hour in 3 (9\%) patients. The episode lasted for less than 24 hours in $12(36 \%)$, and more than 24 hours in 21 (64\%) patients. In anterior wall myocardial infarction atrial fibrillation occurred within 24 hours in $2(7 \%)$ patients, on the second day in 25 (93\%). The episode lasted less than 24 hours in 3 (11\%), 48 hours in (85\%), 72 hours in 1 (4\%) patients. There was a significant difference in the onset and duration of atrial fibrillation in relation to the location of infarction $(P<0.0001)$. Anterior wall myocardial infarction was associated with late onset of atrial fibrillation, increased frequency of heart failure and higher CCU mortality.

Conclusion: The onset of atrial fibrillation in anterior wall myocardial infarction occurred later and lasted longer in comparison to inferior wall myocardial infarction. Increased incidence of heart failure and higher CCU mortality was associated with anterior wall myocardial infarction.

\section{Corresponding Author}

\section{Radha Bhattarai}

Department of Hospital Therapy and Cardiology

Northwestern State Medical University Vasilevsky Ostrov,

Bolshoe Prospect 85, Saint-Petersburg, Russia

Email: radhabhattarai@mail.ru 
the onset and duration. Patients with AF on arrival had a lower mortality risk compared to those developing AF during hospitalization. A similar finding was reported in the GUSTO I trial ${ }^{4-9}$ in which AF which occurred during hospitalization was independently associated with mortality. The presence of AF is associated with a high risk of heart failure and mortality in MI patients, regardless of its timing. Some investigators found no increase in mortality related to the presence of $\mathrm{AF},{ }^{10-13}$ while other studies showed a greater overall early mortality rate in patients with anterior myocardial infarction with AF. ${ }^{14-15}$ In AMI atrial fibrillation is usually transient and may not require treatment. However, if the arrhythmia causes a rapid ventricular rate with severe hypotension or circulatory collapse, cardio version by an immediate synchronized DC shock should be considered. Factors precipitating AF during AMI include atrial ischemia or infarction, right ventricular infarction, pericardial inflammation, acute hypoxia, electrolyte disturbances such as hypokalemia, hemodynamic impairment secondary to LV dysfunction and circulating catecholamines (endogenous or exogenous).

The primary aim of this study was to identify the differences in atrial fibrillation Onset, duration and termination in AMI and to assess the prognosis of new-onset AF during AMI.

\section{METHODS}

It was a single centre prospective observational study, carried out in the coronary care unit of Saint-Petersburg Pokrovskaya hospital, Russia during the period of June 2013 - June 2014. The research protocol was approved by the ethical committee of Northwestern State Medical University. Informed consent was taken from all patients included in the study. Patients included in the study were diagnosed as Anterior Wall MI and Inferior Wall MI with atrial fibrillation according to current national guidelines. Patients with valvular heart disease, $\mathrm{LVEF}<40 \%$, known permanent $\mathrm{AF}$, cardiomyopathy and previous left bundle branch block were excluded from the study.

The study consisted of 60 patients with AF during AMI. Patients were grouped as follows: 1) inferior wall MI 2) anterior wall MI. MI was diagnosed by elevated biochemical markers of myocardial necrosis and ECG changes demonstrating either: 1) ST segment elevation $>1 \mathrm{~mm}$ in two consecutive leads or 2) new or presumed new left bundle branch block along with ischemic symptoms or ST-segment depression or T wave abnormalities. A brief questionnaire that included the history of arrhythmias, thyroid disease, diabetes, hypertension, stroke and family history of ischemic heart disease, were used for primary data collection. Fasting blood glucose, renal function and lipids were measured within 24 hours of admission.

The presence of diabetes was defined by the history or by a fasting glucose level of $>7.1 \mathrm{mmol} / \mathrm{L}$. The presence of hypertension was defined by history of the disease, a systolic blood pressure greater than $140 \mathrm{~mm} \mathrm{Hg}$, or a diastolic blood pressure greater than $90 \mathrm{mmHg}$. Dyslipidemia was defined as history of dyslipidemia and treated by a physician or a total cholesterol level greater than $5.18 \mathrm{mmol} / \mathrm{l}$, low-density lipoprotein greater than or equal to $3.37 \mathrm{mmol} / 1$ and high-density lipoprotein $<1.04 \mathrm{mmol} / \mathrm{l}$. High triglyceride level was defined as greater than $2.3 \mathrm{mmol} / \mathrm{L}$.

Anterior infarction was defined by the presence of ECG changes in leads I, aVL, V1-V6 on the standard 12 lead ECG. Inferior infarction was defined by changes in lead II, III, AVF, true posterior infarction defined by $\mathrm{R} \backslash \mathrm{S}$ in lead V1 greater than one. All patients were admitted within 24 hours of symptoms onset; the mean arrival time being six hours thirty minutes. Twelve lead ECG were recorded daily or whenever the patients had a new event or chest pain, in addition to continuous ECG monitoring for at least 72 hours and for 48 hours after the arrhythmia has terminated. A diagnosis of AF was made on the bases of a 12 lead ECG, by the absence of 'P' wave and a variable degree of baseline fibrillatory activity with irregular R-R intervals. A clinical diagnosis of heart failure was established according to Framingham's criteria with at least one major and two minor criteria. The major criteria include (paroxysmal nocturnal dyspnea, neck vein distention, rales, cardiomegaly, acute pulmonary edema, S3 gallop, increased venous pressure, positive hepatojuglar reflux). The 
minor criteria include (lower extremity edema, night cough, dyspnea on exertion, hepatomegaly, pleural effusion, vital capacity reduced by one third from normal, sinus tachycardia)16. Patients were ranked by Killip class in the following way:

Killip class I included individuals with no clinical signs of heart failure.

Killip class II included individuals with rales or crackles in the lungs, S3 gallop, and elevated jugular venous pressure.

Killip class III included individuals with frank acute pulmonary edema.

Killip class IV included individuals in cardiogenic shock or hypotension (measured as systolic blood pressure lower than $90 \mathrm{mmHg}$ ), and evidence of peripheral hypoperfusion (oliguria, cyanosis or sweating).

Patients received dual anti platelets, statins, received angiotensin converting enzyme inhibitor or angiotensin II receptor blockers and beta blockers as indicated. Primary Percutaneous Coronary Intervention (PCI), thrombolysis, were carried out within the 24 hours of onset of AMI and their outcomes were monitored. Patients were observed daily during the hospital stay and monitored for progress and complications during the recovery phase.

The patients were evaluated for the initial rhythm and after restoration of sinus rhythm electrocardiographically. Spontaneous recovery of AF was defined as ECG with AF which reverted to sinus without any intervention. Pharmacologicalcardioversion(withamiodarone) was done in patients who were hemodynamically stable whereas electrical cardioversion was done in patients who were hemodynamically unstable.

Echocardiogram was performed on the first day of admission, immediately after reversion of AF to sinus rhythm and was repeated after three days, one week, fifteen days, one and three months.

Data management, processing and statistical analysis was carried out using STATISTICA 8. Statistical analysis of survey data included mean values $(\mathrm{M})$ and standard deviation $(\sigma)$ for quantitative assessment for the determination of dispersal of data from the mean. Qualitative indicators are presented in the form of absolute and the relative number of observations, and ranking analysis. For mean comparison we used quantitative indicators such as Student's $\mathrm{t}$-test for the qualitative indicators we used Chi square $(\chi 2)$ - test. Level of statistical significance was accepted at $\mathrm{P}<0.05$.

\section{RESULTS}

Sixty patients with new onset atrial fibrillation during acute myocardial infarction were included, the age ranged from 38-91 years with a mean of $67,7 \pm 12.6$ years. Thirty seven patients were male and twenty three patients were females, the male to female ratio was 1.6:1.

Table 1: Patient Characteristics

\begin{tabular}{|c|c|c|c|}
\hline & $\begin{array}{l}\text { Inferior } \\
\text { Wall MI }\end{array}$ & $\begin{array}{l}\text { Anterior } \\
\text { Wall MI }\end{array}$ & P value \\
\hline $\begin{array}{l}\text { Number of } \\
\text { patients }\end{array}$ & 33 & 27 & \\
\hline Age in years & $66,3 \pm 11,8$ & $69,3 \pm 13,5$ & $>0.05$ \\
\hline Hypertension & $33(100 \%)$ & $26(96 \%)$ & $>0.05$ \\
\hline $\begin{array}{l}\text { Ischemic heart } \\
\text { disease }\end{array}$ & $30(91 \%)$ & $27(100 \%)$ & $>0.05$ \\
\hline $\begin{array}{l}\text { Chronic heart } \\
\text { failure }\end{array}$ & $25(76 \%)$ & $25(93 \%)$ & $>0.05$ \\
\hline Diabetes mellitus & $18(55 \%)$ & $15(56 \%)$ & $>0.05$ \\
\hline Thyrotoxicosis & $1(3 \%)$ & 0 & $>0.05$ \\
\hline
\end{tabular}

The development of AF was observed in 33 (55\%) patients with Inferior Wall Myocardial Infarction (IWMI) and 27 (45\%) with Anterior Wall Myocardial Infarction (AWMI). Onset of AF was more seen in IWMI. In this group AF developed in $30(91 \%)$ patients in the first 24 hours of MI and only $3(9 \%)$ patients AF appeared on the second day. In AWMI group only 2 (7\%) patients AF occurred on the first 24 hours, $19(70 \%)$ patients AF appeared on the second day after MI and $6(23 \%)$ patients on the third day of MI. As shown in Figure 1, there was significant difference in the onset of AF in relation to the location of AMI. The difference is highly significant $(\mathrm{P}<$ 0.0001). 


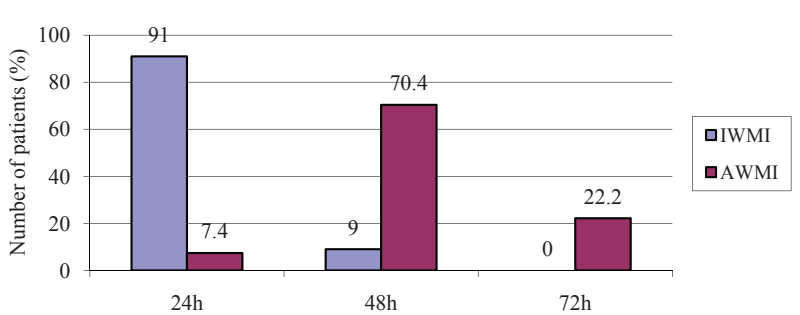

Fig.1 Onset of atrial fibrillation during AMI.

Duration of AF was shorter in IWMI. In this group duration of AF was less than 24 hours in $12(36 \%)$ patients, 24 hours in 21(64\%). Duration of atrial fibrillation was more than 24 hours in AWMI, the episodes lasted for 24 hours in 3 (11\%), for 48 hours in $23(85 \%)$ and for 72 hours in only one $(4 \%)$. As shown in Figure 2, there was significant difference in the duration of AF in relation to the location of MI, The difference was highly significant $(\mathrm{P}<0.0001)$.

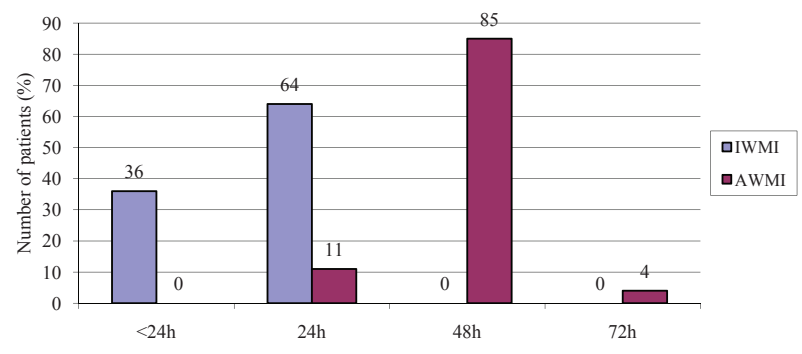

Fig. 2. Duration of atrial fibrillation during acute myocardial infraction.

In IWMI group, sinus rhythm was restored spontaneously in $11(33 \%)$, with amiodarone in 18 $(55 \%)$, and with electrical cardioversion in 4 $(12 \%)$ patients. In AWMI, sinus rhythm was not restored spontaneously, however it was restored with medication in $22(81 \%)$ and with electrical cardioversion in $5(19 \%)$ patients as shown in Figure 3.

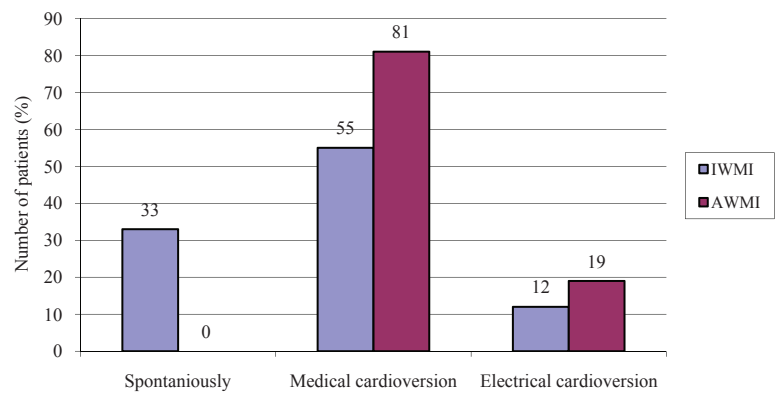

Fig. 3. Mode of AF termination
Heart failure as shown in figure 4 (III, IV Killip Class) was more common among patients with anterior wall myocardial infarction as compared with inferior wall myocardial infarction, The difference is highly significant $(\mathrm{P}<0.005)$.

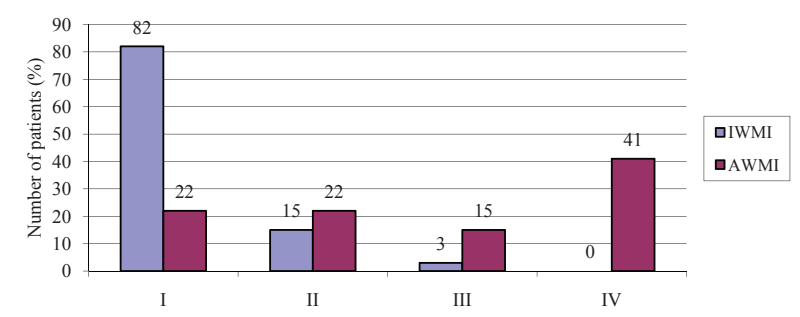

Fig 4 Killip Class

During the CCU stay, we found that AF was associated with significantly mortality in patients with anterior wall myocardial infarction, $7(25 \%)$ vs. $0(0 \%)$, while on the contrary it did not affect the mortality in patients with inferior wall myocardial infarction.

\section{DISCUSSION}

The onset of AF in relation to the onset of infarction is difficult to assess because it is difficult to determine precisely when the infarction has occurred. When both occur before the patient has reached the hospital, it is difficult to determine whether the AF may have been present before the infarction or not, but yet, the transitory nature of the arrhythmia suggests that previously undiagnosed chronic $\mathrm{AF}$ is unlikely. In our study $91 \%$ of the episodes began during the first 24 hours from the onset of symptoms with decreasing frequency throughout the next hours of monitoring in IWMI and in $70 \%$ patients with AWMI, AF occurred on the second day. These results were similar to the study done by Klass and Haywood18 and also agreed with Antman and Braunwald. The higher incidence of AF during the first 24 hours could be explained by the fact that during the process of cell death there will be an increase in the release of catecholamine with electrolytes disturbances especially hypokalemia and hypomagnesaemia; this process ceases with the maturation of infarction. ${ }^{19-24}$ Hod et al investigated the pathogenesis of AF in the early hours of an AMI in a population of patients who were admitted within three hours of the onset AMI. They suggested that acute left atrial ischemia is the patho-physiological mechanism of early AF. The majority of episodes (64\%) of $\mathrm{AF}$ in our patients lasted for 24 hours and less than 24 hours in $(36 \%)$ which was spontaneously reverted, it concurred with Stannard and Klass who reported 
that AF complicating AMI is usually transient. We found significant differences in the onset and duration of AF in relation to the location of MI but Mohanad AL-Jashami ${ }^{17}$ demonstrated that there was no relation of AF to the site of infarction. Others ${ }^{1,4,13,18}$ have also demonstrated an equal distribution between anterior and posterior infarcts associated with AF, Robert and Kelly ${ }^{25}$ mentioned that atrial arrhythmias were more common with inferior infarction particularly with right ventricular involvement. Others ${ }^{9,26}$ stated that $\mathrm{AF}$ occurs more frequently following anterior than inferior infarcts. Heart failure (III, IV Killip Class) was more common among patients with anterior wall myocardial infarction as compared with inferior wall myocardial infarction. Left ventricular failure appears to be an important mechanism of AF in anterior myocardial infarction, which in turn resulted in acute left atrial hypertension and distention. ${ }^{18,26}$ The increased atrial size would permit the coexistence many re-entrant circuits and is an important factor for the occurrence and perpetuation of $\mathrm{AF}^{23} \mathrm{We}$ found that $\mathrm{AF}$ significantly increases the mortality rate in patients with anterior wall myocardial infarction $7 \%$ vs. $0 \%$, while on the contrary AF did not affect the mortality in patients with inferior wall myocardial infarction.

Our data and previously reported studies ${ }^{1,8,18-20}$ showed that patients with AF tended to have a higher mortality. Both Stanard and Stomman1 and Klass and Haywood ${ }^{18}$ indicated that AF was in itself a benign complication of myocardial infarction and that its prognostic significance related to the severity of concurrent complications. Cristal et $\mathrm{al}^{8}$ showed that there was no cause and effect relationship between $\mathrm{AF}$ and the high mortality associated with it and the prognosis is related to the mechanism of production of AF and not to the arrhythmia itself. On the other hand, Helmers et a $\mathrm{l}^{19}$ considered AF an objective factor pointing towards high risk patients.

According to the GUSTO III investigators ${ }^{27}$, there was no association between the use of amiodarone or electrical cardioversion and thirty day or one year mortality.

There were several limitations to be considered in the interpretation of our study. First, this was a single center study. The number of patients studied with new onset AF was inadequate. Other potential risk factors described in the literature, such as diastolic function were not taken into account. Finally there was no long term follow up.

\section{CONCLUSION}

In our opinion, $\mathrm{AF}$ is not an uncommon arrhythmia that complicates myocardial infarction early in the disease. The onset of AF in AWMI occurred late and lasted longer than those in inferior wall myocardial infarction. The incidence of spontaneous conversion of AF in AWMI is significantly less compared to IWMI. This might be because of AF in IWMI is associated with atrial infarction/ischemia or vagal AF. Higher frequency of heart failure and higher CCU mortality were associated with AWMI. Such patients should be targeted for earlier and more aggressive treatment. The management of patients developing atrial fibrillation after acute myocardial infarction should include intensive clinical surveillance, chronic anticoagulation and cardioversion whenever possible.

\section{REFERENCES}

1. Schmitt J, Duray G, Gersh BJ, et al. Atrial fibrillation in acute myocardial infarction: a systematic review of the incidence, clinical features and prognostic implications. Eur Heart $\mathrm{J}$ 2009;30:1038-45.

2. Lau DH, Huynh LT, Chew DP, et al. Prognostic impact of types of atrial fibrillation in acute coronary syndromes. Am J Cardiol 2009;104:1317-23.

3. Podolecki T, Lenarczyk R, Kowalczyk J, et al. Effect of type of atrial fibrillation on prognosis in acute myocardial infarction treated invasively. Am J Cardiol 2012;109:1689-93.

4. Jabre P, Roger VL, Murad MH, et al. Mortality associated with atrial fibrillation in patients with myocardial infarction: a systematic review and meta-analysis. Circulation 2011;123:1587-93.

5. Cappato R. Atrial fibrillation complicating acute myocardial infarction: how should it be interpreted and how should it be treated and prevented? Eur Heart J 2009;30:1035-7. 
6. Zoni Berisso M, Carratino L, Ferroni A, et al. The relation between supraventricular tachy arrhythmias and left ventricular dysfunction after acute myocardial infarction. Acta Cardiol1988;43:689-701.

7. Sugiura T, Iwasaka T, Takahashi N, et al. Atrial fibrillation in inferior wall Q-wave acute myocardial infarction. Am J Cardiol1991;67:1135-6.

8. Kobayashi Y, Katoh T, Takano T, et al. Paroxysmal atrial fibrillation and flutter associated with acute myocardial infarction:hemodynamic evaluation in relation to the development of arrhythmias and prognosis. Jpn CirJ1992;56:111.

9. Yoshizaki T, Umetani K, Ino Y, et al. Activated inflammation is related to the incidence of atrial fibrillation in patients with acute myocardial infarction. Intern Med2012;51:1467-71.

10. Julian DG, Vanlentine PA, Miller GG. Disturbance of the rate, rhythm and conduction in acute myocardial infarction. Am J Med 1994; 37:915.

11. Meltzer LE, Kitchell JB. The incidence of arrhythmia associated with acute myocardial infarction. Prog Cardvasc Disease1996; 9:50.

12. Fluck D, Olsen E, Pentcost BL, et al. Natural history and clinical significance of arrhythmias after myocardial infarction. Br Heart J 1997; 29:170.

13. Jewitt DE, Balcon R. Raftery EB, et al. Incidence and management of supraventricular arrhythmia after acute myocardial infarction. Lancet 1996; 2:734.

14. Cristal N, Peterburg I Zwarberg J. AF developing in the acute phase of myocardial infarction Prognostic implication. Chest 1997;70: 8 .

15. Antman EM, Braunwald E. Arrhythmia in acute myocardial infarction. In Braunwald E ed. Heart disease A textbook of cardiovascular medicine. 4th ed. Philadelphia. W. B . Saunder, s Co. 1992, pp 1239-1249.

16. Braunwald E. Normal and abnormal myocardial function. In: Harrison, s, Principles of internal medicine. 15th ED, New York, McGraw-Hill 2002; 1278-1298.

17. Mohanad al Jashami Atrial fibrillation in acute myocardial infarction Medical Journal of Babylon 2008;5:2.

18. Klass M , Haywood LJ. AF associated with acute myocardial infarction. A study of 34 cases. Am Heart J1990,79: 752.

19. Helmers C, Lundman T, Mogenson L, et al. Atrial fibrillation in acute myocardial infarction. Acta Med Scand 1993; 193:39.

20. Hunt D, Sloman G, Penington C. Effect of AF on prognosis of AMI. Br Heart J1998; 40:303.

21. Hod H, Lew AS, Keltal M, et al. Early AF during evolving myocardial infarction a consequence of impaired left atrial perfusion. Circulation 1997; 75(1): 146.

22. Goldberg RJ, Seely D, Becker RC, et al. Impact of AF on the in-hospital and long term survival of patients with AMI: A community wide perspective. Am Heart J 1999; 119:996.

23. Janse MJ .Why does AF occur? Euro H J 1997; 18:12-18.

24. Lawson DH, Current medicine, 2nd ed, Edinburg, Churchill Livingstone, 1999: 35-40.

25. Roberts R, AMI. In Kelleyd, Textbook of Internal Medicine. New York. J.B Lippincott Co. 1998, pp 152-168.

26. Desanctis RW, Block p, Hutter AM, Tachyarrhythmia in myocardial infarction. Circulation 1992; 45: 681.

27. C-K Wong, H D White, R G Wilcox et al. Management and outcome of patients with atrial fibrillation during acute myocardial infarction the GUSTO-III investigators Heart 2002;88:357-362.

28. BRIAN S. CRENSHAW, SAMUEL R et al. Atrial Fibrillation in the Setting of Acute Myocardial Infarction: The GUSTO-I Experience J Am Coll Cardiol 1997;30:406-13. 